\title{
Paraprotein estimation: a comparison of immunochemical and densitometric techniques
}

\author{
A. M. SMITH AND R. A. THOMPSON
}

From the Regional Immunology Laboratory, East Birmingham Hospital, Bordesley Green East, Birmingham B9 5ST, UK

SUMMARY Paraproteins have been estimated by both immunochemical methods and densitometric analysis of electrophoretic strips. Correlation between the results obtained by these two methods, although generally good for assessing trends, varied between patients.

Immunochemical methods are routinely used to estimate immunoglobulins. However, since monoclonal immunoglobulins often differ considerably in antigenic expression by comparison with normal immunoglobulins of the same class, electrophoresis combined with densitometry may offer advantages in measuring such proteins (Hobbs et al., 1966). It is common experience that individual values estimated by these two methods may differ considerably. In extreme instances the 'immunochemical value' for the immunoglobulin class to which the monoclonal protein belongs may exceed the total serum proteins as estimated by the Biuret technique. What is important is the consistency of measurement by either method and the manner in which measurements reflect the changes in the clinical state of the patient. Diagnosis itself does not depend on quantitation, although the absolute value of the paraprotein may contribute towards a decision as to the likelihood of malignancy. This paper presents the results of a comparison of the two methods.

\section{Patients and sera}

A total of 186 serum samples were analysed including serial specimens (116 in all) from 11 patients with clinical myelomatosis or primary macroglobulinaemia and one with a monoclonal gammopathy. An additional 70 samples were obtained from a further 40 patients, the majority of whom had established myelomatosis, although serial serum samples were not available. All patients had monoclonal proteins in one of the three major immunoglobulin classes (IgG, IgA, IgM).

Electrophoresis of sera was performed in agarose (Corning ACI System) with densitometric estima-

Received for publication 17 May 1978 tion of the paraprotein band (Varian MPS spectro- $\overrightarrow{\vec{G}}$ photometer) after staining with amido black. Total protein estimations were made using the Biuret ${ }^{3}$ method of Doumas (1975). The coefficient of variation $\vec{\square}$ of the densitometric analysis was $5.9 \%$.

Immunochemical estimation of the relevant im- $\mathbb{\Phi}$ munoglobulin was performed using single radial immunodiffusion (Mancini et al., 1965) with a coefficient of variation in this department of $7.3 \%$ The antisera used were obtained from Dr D. Catt,$\infty$ Department of Experimental Pathology, Birming ham University, having been raised against normis human $\gamma$ chain, or pooled monoclonal $\alpha$ or $\mu$ chains, and absorbed to render them specific. Three large batches of $\operatorname{IgG}$ and $\operatorname{IgA}$ antisera and a single $\frac{\mathcal{O}}{\mathbb{Q}}$

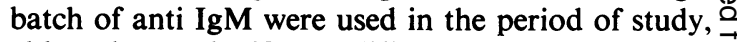
although no significant differences were found in $\overline{0}$ between-batch estimations of normal and pathological sera.

Initial typing of the paraprotein was by immunoelectrophoresis of serum against monospecific antisera.

\section{Results}

Figure $1(\mathrm{a}, \mathrm{b}, \mathrm{c})$ shows the comparison between the two methods for all 186 samples. There is a highly significant overall correlation $(\mathrm{r}=0.83 ; \mathrm{P}=0.001)$ 음 between the two methods and this is also the case with respect to individual Ig classes (Table 1). On $N$ plotting the regression equation for each Ig class the $N$ slope for IgG is $\mathbf{0 . 8 8}$, indicating that both methods $N$ give comparable results for IgG. However, for IgA $\mathrm{\omega}$ and IgM, the slopes are 0.62 and 0.76 respectively, showing a slight tendency for higher values by radial diffusion. This may be a reflection of the difference in standards for the methods employed; or since the anti-IgA and anti-IgM antisera used in 1156 
(a)
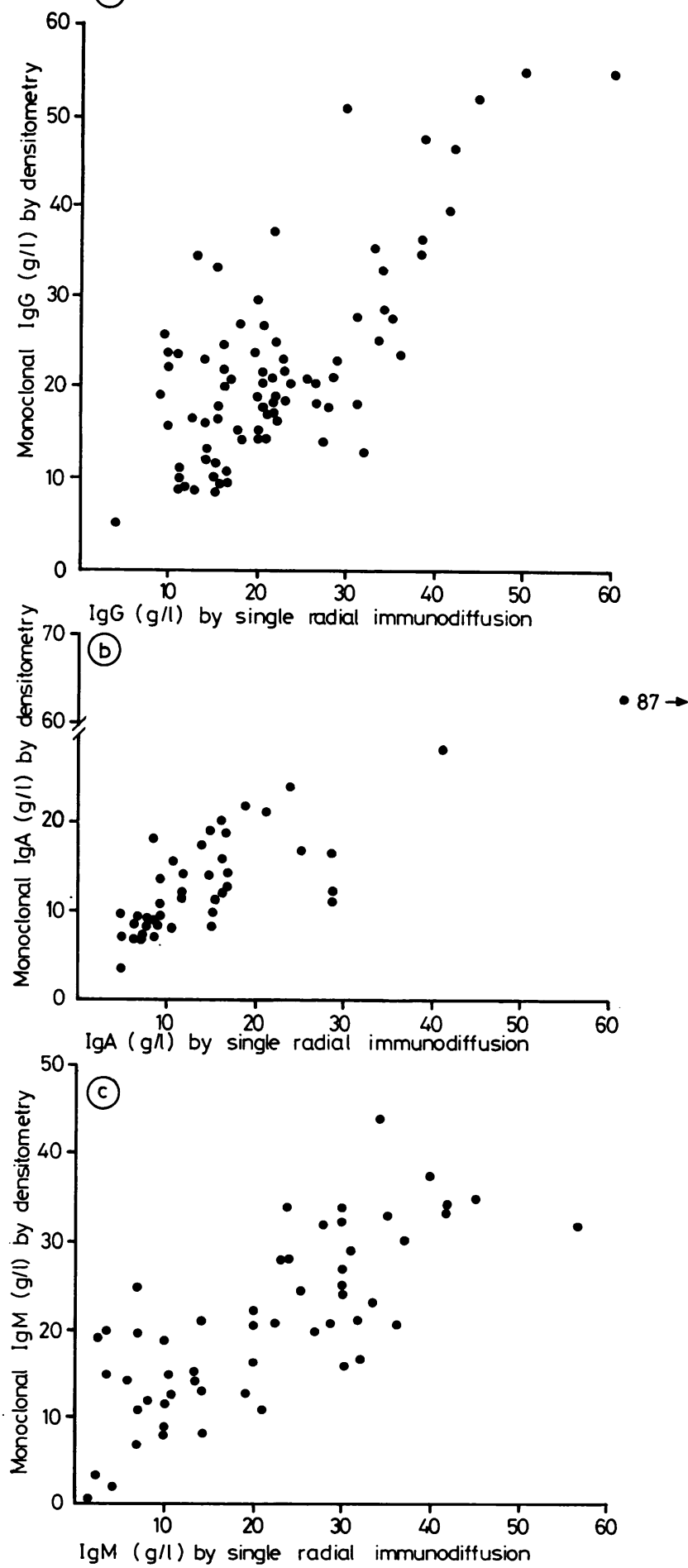

Fig. 1 Comparison between immunochemical and densitometric measurements of monoclonal proteins in the classes $\operatorname{Ig} G(a), \operatorname{IgA}(b)$, and $\operatorname{Ig} M(c)$. 

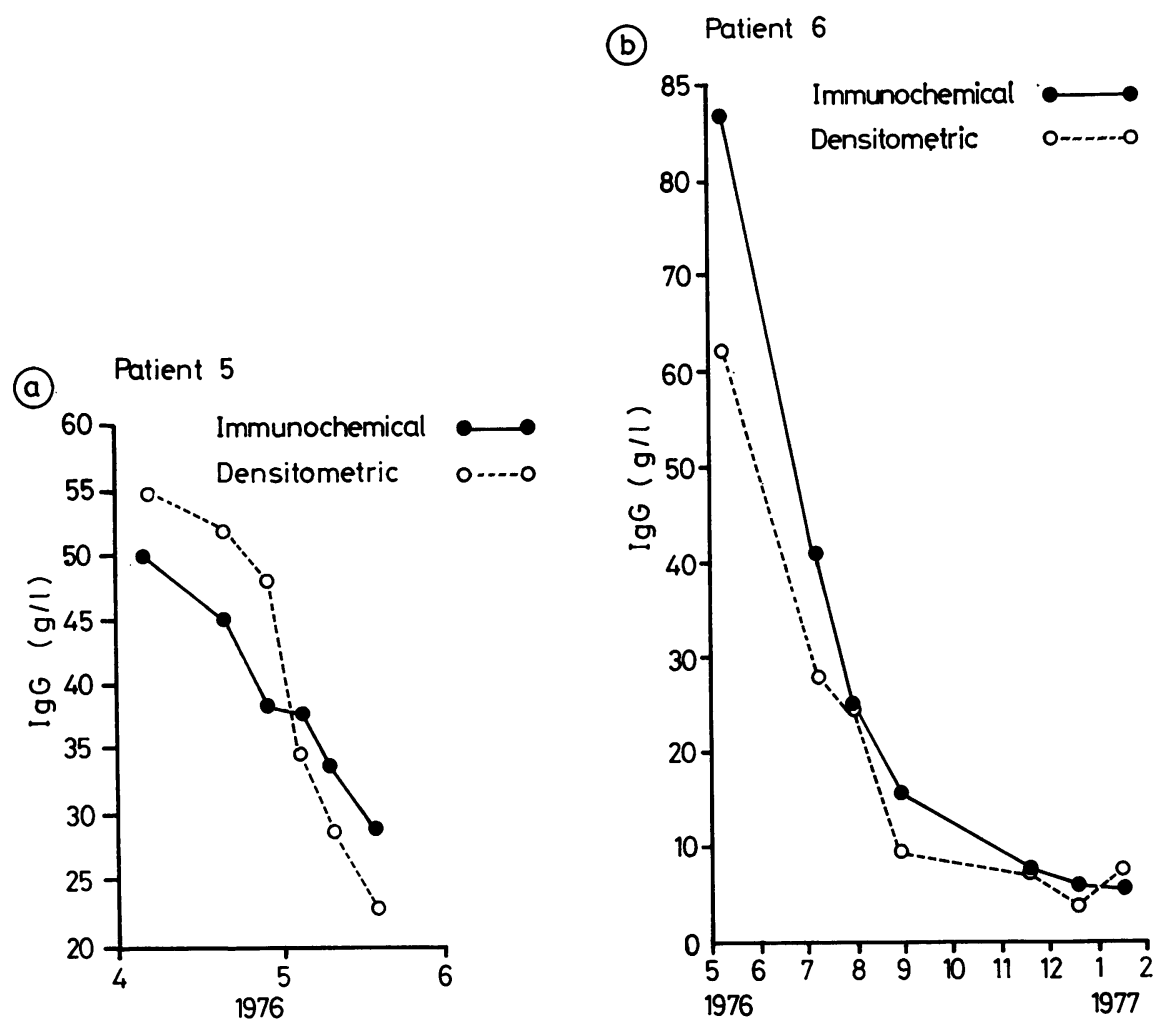

Fig. 2 Sequential changes in the monoclonal protein levels of patients 5 and 6 (Table 2).

Table 1 Correlation between immunochemical and densitometric analysis of monoclonal proteins

\begin{tabular}{lcll}
\hline $\begin{array}{l}\text { Ig class of } \\
\text { monoclonal proteins }\end{array}$ & $\begin{array}{l}\text { Number of } \\
\text { estimations }\end{array}$ & $\begin{array}{l}\text { Correlation } \\
\text { coefficient }\end{array}$ & P value \\
\hline G & 87 & 0.85 & $<0.001$ \\
A & 43 & 0.90 & $<0.001$ \\
Total & 56 & 0.76 & $<0.001$ \\
\hline
\end{tabular}

the immunochemical method are raised against monoclonal antigens, it may be due to the antigenic differences between the monoclonal proteins and the polyclonal standard.

On separately analysing samples from different patients (Table 2) it appears that the values by the two methods are well correlated in some patients (5 and 6) but not in others $(7,9,10)$. Figure $2(a, b)$ shows the changes in paraprotein level with time, estimated by both techniques, for two patients ( 5 and 6). Both methods reflect the same trend in paraprotein levels, and either method could have been used in the assessment of the response to treatment.

The same cannot be said of other patients in
Table 2 Correlation between the two methods in serial samples from patients

\begin{tabular}{|c|c|c|c|c|}
\hline Ig class & $\begin{array}{l}\text { Patient } \\
\text { number }\end{array}$ & $\begin{array}{l}\text { Number of } \\
\text { estimations }\end{array}$ & $\begin{array}{l}\text { Correlation } \\
\text { coefficient }\end{array}$ & P value \\
\hline $\mathbf{G}$ & 1 & 11 & 0.73 & $<0.01$ \\
\hline $\mathbf{G}$ & 2 & 7 & 0.51 & NS \\
\hline $\mathbf{G}$ & 3 & 18 & 0.57 & $<0.05$ \\
\hline $\mathbf{G}$ & 4 & 5 & 0.78 & $<0.05$ \\
\hline $\mathbf{G}$ & 5 & 6 & 0.93 & $<0.01$ \\
\hline $\mathbf{A}$ & 6 & 7 & 0.98 & $<0.001$ \\
\hline $\mathbf{A}$ & 7 & 8 & 0.05 & NS \\
\hline $\mathbf{A}$ & 8 & 21 & 0.63 & $<0.01$ \\
\hline $\mathbf{M}$ & 9 & 9 & 0.43 & NS \\
\hline $\mathbf{M}$ & 10 & 6 & 0.03 & NS \\
\hline $\mathbf{M}$ & 11 & 11 & 0.68 & $<0.02$ \\
\hline $\mathbf{M}$ & 12 & 7 & 0.83 & $<0.01$ \\
\hline
\end{tabular}

whom individual values showed no significant cor- $\mathcal{O}$ relation. Patient 2 (Fig. 3) had a monoclonal IgG, $\omega$ slight Bence-Jones proteinuria, and a very slight ${ }^{\sigma}$ plasmacytosis of the marrow, and her clinicians ${ }_{C}$ decided not to treat her with cytotoxic drugs. She also had dermatological and bowel symptoms, but ${ }^{+}$ her haematological state remained constant over the $\frac{T}{0}$ period represented in the figure. The densitometric $\frac{}{\oplus}$ 
Patient 2

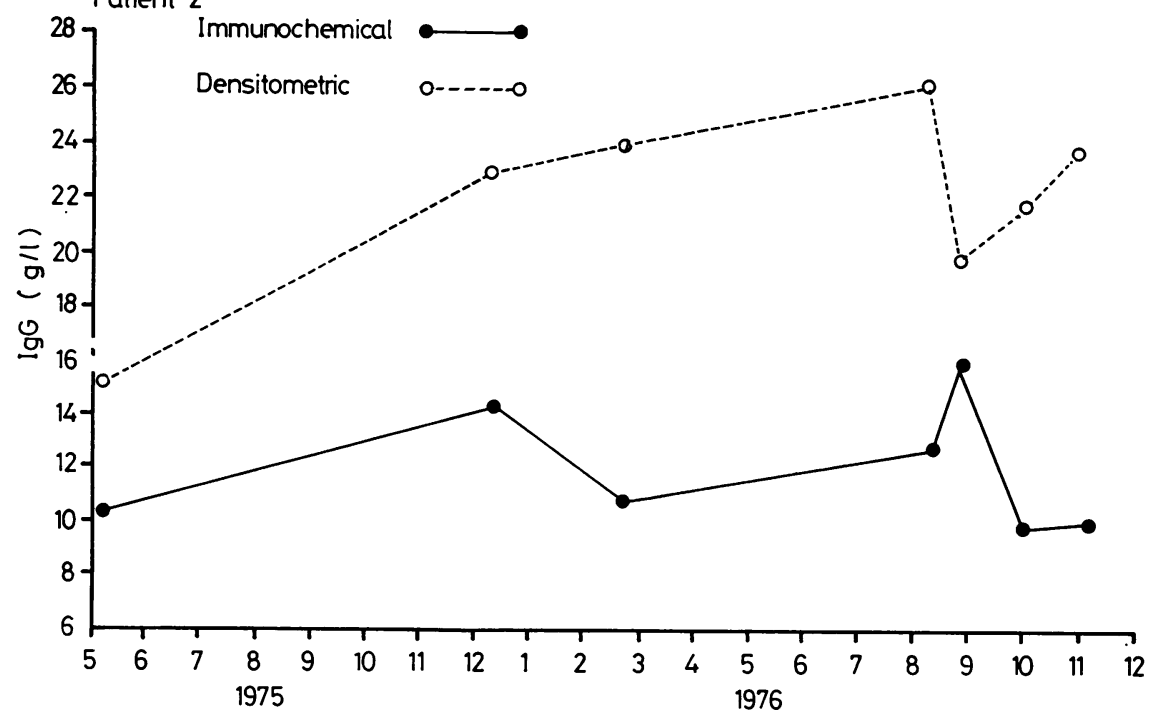

Fig. 3 Sequential changes in the monoclonal protein level of patient 2 (Table 2).

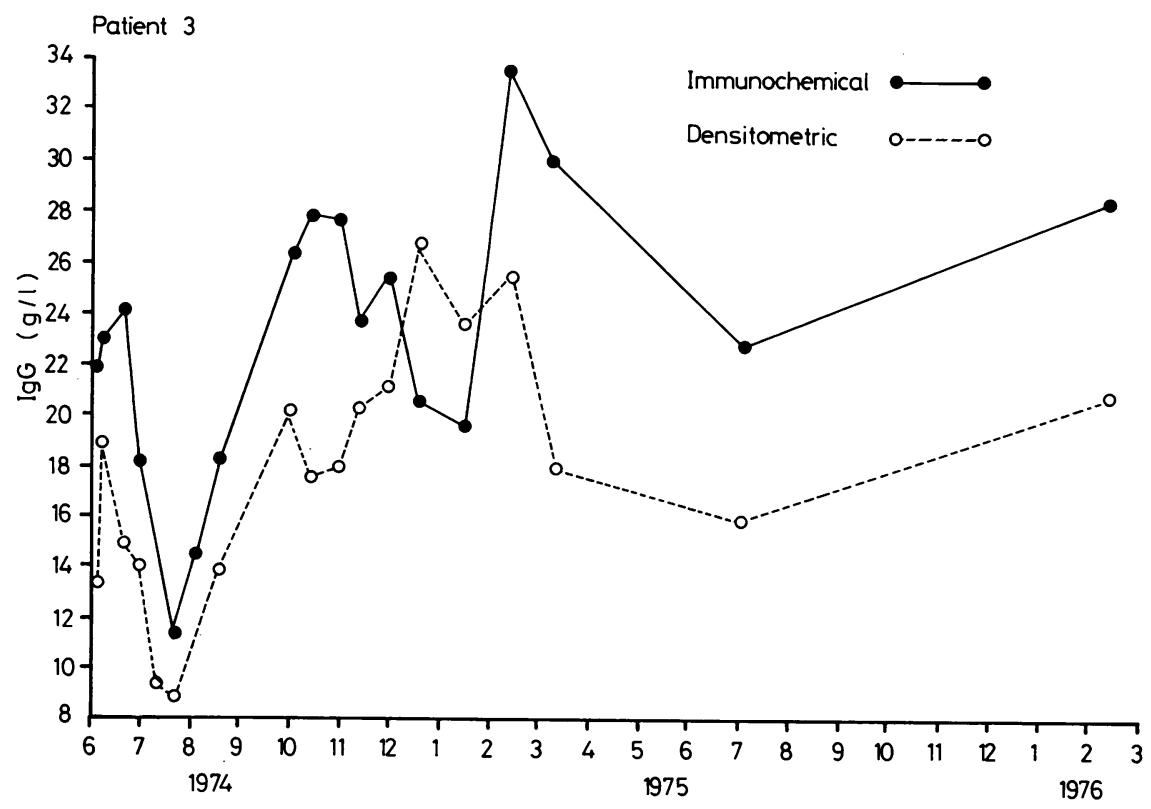

Fig. 4 Sequential changes in the moroclonal protein level of patient 3 (Table 2).

estimations indicated a gradual increase in the monoclonal protein over a period of two years, while the immunochemical technique showed little overall change.

Patient 3 (Fig. 4) had an IgG myeloma and was started on treatment in June 1974, after which there was a sharp fall in the levels of monoclonal protein and IgG with a subsequent rise and variation over the next two years. Although broad trends over several months are in the same direction, interpretation of 
individual values could be different, depending on the method used.

\section{Discussion}

While there is a clear overall correlation between the immunochemical estimation of immunoglobulin classes containing a monoclonal protein and the densitometric quantitation of the monoclonal protein, there appears to be greater concordance between the two methods in some patients than in others. This is at variance with some authors, who suggest that results by both methods are always comparable (Dugue et al., 1971). Moreover, in those patients reported here, in whom the correlation between the two methods was poor, there was no consistency as to whether either method corresponded to the clinical progress of the patient. Thus, although monitoring of the myeloma protein level can be helpful in the management of the clinical case, and densitometry has been advocated as the method of choice, neither method is clearly superior for this purpose. The ideal method perhaps would be to use an anti-'idiotype' antiserum, raised against the specific antigenic determinants of each myeloma protein (Hopper and Nisonoff, 1971). Such sera do not react with normal immunoglobulins. However, this is not a practical solution in routine clinical practice, and it may be wise to employ both methods initially until the pattern of response to treatment emerges.

Caution must be observed in the use of immmunochemical techniques for this purpose. Because of the problem of non-parallel dilution curves in the single radial diffusion test between myeloma and normal immunoglobulins, it is necessary to measure the serum level from a given patient using the same dilution on each occasion. Moreover, if different batches of antisera are used at different times, then it is preferable in analyses of serial specimens for any specimen to be estimated at the same time as a stored aliquot of the previous specimen from the same patient.

\section{References}

Doumas, B. T. (1975). Standards for total serum protein assays-a collaborative study. Clinical Chemistry, 21, 1159-1166.

Dugue, M., Rousselet, F., Kahn, M. F., and Girard, M. L. (1971). Études biologiques sur 559 cas de paraprotéinémies. Clinica Chimica Acta, 33, 75-86.

Hobbs, J. R., Slot, G. M. J., Campbell, C. H., Clein, G. P., Scott, J. T., Crowther, D., and Swan, H. T. (1966). Six cases of gamma-D myelomatosis. Lancet, 3 , 614-618.

Hopper, J. E., and Nisonoff, A. (1971). Individual antigenic specificity of immunoglobulins. Advances in Immunology, 13, 57-99.

Mancini, G., Carbonara, A. O., and Heremans, J. F尺 $\vec{\varphi}$ (1965). Immunochemical quantitation of antigens be single radial immuno-diffusion. Immunochemistry, 235-254.

Requests for reprints to: Dr R. A. Thompson, Regional Immunology Laboratory, East Birmingham Hospital, Bordesley Green East, Birmingham B9 5ST, UK. 